\title{
Frequency of EGFR T790M mutation and multimutational profiles of rebiopsy samples from non-small cell lung cancer developing acquired resistance to EGFR tyrosine kinase inhibitors in Japanese patients
}

Ryo Ko ${ }^{1,2}$, Hirotsugu Kenmotsu ${ }^{1 *}$, Masakuni Serizawa ${ }^{3}$, Yasuhiro Koh ${ }^{3,4}$, Kazushige Wakuda', Akira Ono ${ }^{1}$, Tetsuhiko Taira', Tateaki Naito ${ }^{1}$, Haruyasu Murakami ${ }^{1}$, Mitsuhiro Isaka ${ }^{5}$, Masahiro Endo ${ }^{6}$, Takashi Nakajima', Yasuhisa Ohde ${ }^{5}$, Nobuyuki Yamamoto ${ }^{1,4}$, Kazuhisa Takahashi ${ }^{2}$ and Toshiaki Takahashi ${ }^{1}$

\begin{abstract}
Background: The majority of non-small cell lung cancer (NSCLC) patients with epidermal growth factor receptor (EGFR) mutation eventually develop resistance to EGFR tyrosine kinase inhibitors (TKls). Minimal information exists regarding genetic alterations in rebiopsy samples from Asian NSCLC patients who develop acquired resistance to EGFR-TKIs.
\end{abstract}

Methods: We retrospectively reviewed the medical records of patients with NSCLC harboring EGFR mutations who had undergone rebiopsies after developing acquired resistance to EGFR-TKIs. We analyzed 27 practicable samples using a tumor genotyping panel to assess 23 hot-spot sites of genetic alterations in nine genes (EGFR, KRAS, BRAF, PIK3CA, NRAS, MEK1, AKT1, PTEN, and HER2), gene copy number of EGFR, MET, PIK3CA, FGFR1, and FGFR2, and ALK, ROS1, and RET fusions. Additionally, 34 samples were analyzed by commercially available EGFR mutation tests.

Results: Sixty-one patients underwent rebiopsy. Twenty-seven samples were analyzed using our tumor genotyping panel, and 34 samples were analyzed for EGFR mutations only by commercial clinical laboratories. Twenty-one patients (34\%) had EGFR T790M mutation. Using our tumor genotyping panel, MET gene copy number gain was observed in two of 27 (7\%) samples. Twenty patients received continuous treatment with EGFR-TKIs even after disease progression, and 11 of these patients had T790M mutation in rebiopsy samples. In contrast, only 10 of 41 patients who finished EGFR-TKI treatment at disease progression had T790M mutation. The frequency of T790M mutation in patients who received continuous treatment with EGFR-TKIs after disease progression was significantly higher than that in patients who finished EGFR-TKI treatment at disease progression (55\% versus 24\%, $p=0.018$ ).

Conclusions: The frequency of T790M mutation in this study was lower than that in previous reports examining western patients. These results suggest that continuous treatment with EGFR-TKI after disease progression may enhance the frequency of EGFR T790M mutation in rebiopsy samples.

Keywords: Non-small cell lung cancer, Epidermal growth factor receptor mutation, Rebiopsy, T790M mutation

\footnotetext{
* Correspondence: h.kenmotsu@scchr.jp

${ }^{1}$ Division of Thoracic Oncology, Shizuoka Cancer Center, 1007

Shimonagakubo, Nagaizumi-cho, Sunto-gun, Shizuoka 411-8777, Japan

Full list of author information is available at the end of the article
} 


\section{Background}

Lung cancer is the most common cause of cancer-related deaths, and non-small cell lung cancer (NSCLC) accounts for approximately $85 \%$ of all lung cancers $[1,2]$. Over $70 \%$ of patients with NSCLC have advanced disease at the time of diagnosis, and prognosis is generally poor [3]. Recently, molecular targeted therapies have been developed and have provided a remarkable benefit to NSCLC patients with specific genetic alterations. In particular, NSCLC with mutation in the epidermal growth factor receptor (EGFR) gene are sensitive to EGFR blockade with specific tyrosine kinase inhibitors (TKIs). EGFR-TKIs are efficacious in patients with NSCLC harboring EGFR mutations as demonstrated in prospective clinical trials [4-8]. However, in spite of this efficacy almost all patients with EGFR-mutant NSCLC develop resistance to EGFR-TKIs.

Various mechanisms of resistance to EGFR-TKIs have been identified, and understanding these is critical for development of effective treatment strategies for EGFRTKI-resistant NSCLC. The major mechanism of acquired resistance reported is secondary T790M mutation on exon 20 on the EGFR gene [9-12]. This secondary mutation enhances ATP-binding affinity of EGFR-mutated cells. Since EGFR-TKIs are competitive ATPinhibitors, their efficacy is decreased in the face of the T790M mutation [13]. Additional mechanisms include amplification of the MET gene [11, 12, 14], PIK3CA mutation $[11,15], B R A F$ mutation [16], epithelial-tomesenchymal transition (EMT) [11], and small cell lung cancer (SCLC) transformation [11, 12].

Several studies have examined the mechanisms and frequency of EGFR-TKI resistance, though minimal data regarding Japanese patients exist. Furthermore, the clinical factors that influence the frequency of acquired resistance mutations, especially T790M, remain unclear. This study aimed to analyze the causes of acquired resistance to EGFR-TKIs in Japanese patients with NSCLC, and to evaluate clinical factors related the frequency of T790M mutation.

\section{Methods}

\section{Patients}

We reviewed the medical records of consecutive patients with NSCLC harboring EGFR mutations who had undergone rebiopsies based on physician's decision in the cases of acquired resistance to EGFR-TKI. Most rebiopsy samples were obtained from sites assessed as disease progression by imaging. Patients were treated at the Shizuoka Cancer Center between September 2002 and August 2014. Acquired resistance was defined according to Jackman's criteria [17]. The criteria defined acquired resistance as progression while receiving EGFR-TKI, after initial response or durable stable disease ( $>6$ months). The written informed consent regarding EGFR mutational analysis was obtained from most patients, and verbal informed was from some patients since EGFR mutational analysis was performed under the Japanese insurance system. Additionally, some patients were enrolled in the Shizuoka Lung Cancer Mutation Study [18], and these samples were analyzed using our tumor genotyping panel. This study protocol was approved by the Institutional Review Board of Shizuoka Cancer Center under number 27-J102-27-1-3.

\section{Mutational profiling}

A tumor genotyping panel was designed to assess 23 hotspot sites of genetic alterations in 9 genes (EGFR, KRAS, BRAF, PIK3CA, NRAS, MEK1, AKT1, PTEN, and HER2), gene copy number of EGFR, MET, PIK3CA, FGFR1, and FGFR2, and ALK, ROS1, and RET fusions using pyrosequencing plus capillary electrophoresis, quantitative polymerase chain reaction (PCR), and reverse transcription PCR, respectively (Table 1). We analyzed samples from patients enrolled in the Shizuoka Lung Cancer Mutation Study, using this tumor genotyping panel. The other samples were analyzed for EGFR mutations using the Scorpion ARMS or Cycleave methods by a commercial clinical laboratory (SRL Inc., Tokyo, Japan) (see Additional file 1).

\section{Evaluation of efficacy}

Responsiveness to EGFR-TKI treatment was evaluated according to the Response Evaluation Criteria in Solid Tumors version 1.1 [19]. Progression-free survival (PFS) was defined as the period between the start of EGFRTKI treatment and progressive disease or death from any cause. Overall survival (OS) was defined as the period between the start of EGFR-TKI treatment and the date of death from any cause.

\section{Statistical analysis}

All categorical variables were analyzed by the chi-square test or Fisher's exact test, as appropriate. Continuous variables were analyzed using the Mann-Whitney test. Logistic regression analyses were used to adjust for potential confounding factors. All $p$ values $<0.05$ were considered statistically significant. All analyses were performed using JMP 10 for Windows statistical software (SAS Institute Japan Inc., Tokyo, Japan).

\section{Results}

\section{Patient characteristics}

Sixty-one patients with NSCLC harboring EGFR mutations, and who had undergone rebiopsy after acquired resistance to EGFR-TKI at the Shizuoka Cancer Center were included in this study. Patient characteristics are shown in Table 2. The median age (range) was 64 (39-84) years, and most patients were female (72\%) and never-smokers. 
Table 1 Multiplexed tumor genotyping panel

\begin{tabular}{|c|c|c|c|}
\hline Gene name & Position & AA mutant & Nucleotide mutant \\
\hline \multirow[t]{7}{*}{ EGFR } & G719 & G719 & $2155 \mathrm{G}>\mathrm{T} / \mathrm{A}$ \\
\hline & & G719A & $2156 G>C$ \\
\hline & exon 19 & Deletion & \\
\hline & T790 & T790M & $2369 C>T$ \\
\hline & exon20 & Insertion & \\
\hline & L858 & L858R & $2573 \mathrm{~T}>\mathrm{G}$ \\
\hline & L861 & L861Q & $2582 \mathrm{~T}>\mathrm{A}$ \\
\hline \multirow[t]{7}{*}{ KRAS } & G12 & $\mathrm{G} 12 \mathrm{C} / \mathrm{S} / \mathrm{R}$ & $34 \mathrm{G}>\mathrm{T} / \mathrm{A} / \mathrm{C}$ \\
\hline & & G12V/A/D & $35 G>T / C / A$ \\
\hline & G13 & G13C/S/R & $37 \mathrm{G}>\mathrm{T} / \mathrm{A} / \mathrm{C}$ \\
\hline & & G13D/A & $38 \mathrm{G}>\mathrm{A} / \mathrm{C}$ \\
\hline & Q61 & Q61K & $181 C>A$ \\
\hline & & Q61R/L & $182 \mathrm{~A}>\mathrm{G} / \mathrm{T}$ \\
\hline & & Q61H & $183 \mathrm{~A}>\mathrm{T} / \mathrm{C}$ \\
\hline \multirow[t]{4}{*}{ BRAF } & G466 & G466V & $1397 G>T$ \\
\hline & G469 & G469A & $1406 G>C$ \\
\hline & L597 & L597V & $1789 C>G$ \\
\hline & V600 & V600E & $1799 \mathrm{~T}>\mathrm{A}$ \\
\hline \multirow[t]{3}{*}{ PIK3CA } & E542 & E542K & $1624 G>A$ \\
\hline & E545 & E545K/Q & $1633 G>A / C$ \\
\hline & $\mathrm{H} 1047$ & H1047R & $3140 A>G$ \\
\hline \multirow[t]{2}{*}{ NRAS } & Q61 & Q61K & $181 C>A$ \\
\hline & & Q61L/R & $182 \mathrm{~A}>\mathrm{T} / \mathrm{G}$ \\
\hline \multirow[t]{3}{*}{ MEK1 (MAP2K1) } & Q56 & Q56P & $167 A>C$ \\
\hline & K57 & K57N & $171 \mathrm{G}>\mathrm{T}$ \\
\hline & D67 & D67N & $199 G>A$ \\
\hline AKT1 & E17 & E17K & $49 G>A$ \\
\hline PTEN & R233 & R233 & $697 C>T$ \\
\hline HER2 & exon20 & Insertion & \\
\hline
\end{tabular}

All patients had been diagnosed with adenocarcinoma of the lung with activating EGFR mutations at initial diagnosis. The types of EGFR mutations before the initial EGFRTKI treatment were exon 19 deletion in 37 patients (61\%), exon 21 L858R in 19 patients (31\%), and other/ double EGFR mutations in five patients (8\%). Thirty-nine patients (64\%) were treated with EGFR-TKI as first-line therapy. Twenty-two patients (36\%) received EGFR-TKI as second or subsequent-line therapy. Forty-nine patients (80\%) were treated with gefitinib, seven patients (12\%) with erlotinib, and five patients (8\%) with other EGFRTKIs including afatinib. All patients received EGFR-TKI monotherapy. Twenty patients received continuous treatment with EGFR-TKI more than 30 days after disease progression, and 41 patients finished EGFR-TKI treatment within 29 days after diagnosis of disease progression.
Table 2 Patient characteristics analyzed in our study $(n=61)$

\begin{tabular}{|c|c|}
\hline \multicolumn{2}{|l|}{ Age, year } \\
\hline Median & 64 \\
\hline Range & $39-84$ \\
\hline \multicolumn{2}{|l|}{ Sex, n (\%) } \\
\hline Female & $44(72 \%)$ \\
\hline Male & $17(28 \%)$ \\
\hline \multicolumn{2}{|c|}{ Smoking history, n (\%) } \\
\hline Never & $44(72 \%)$ \\
\hline Former/Current & $17(28 \%)$ \\
\hline \multicolumn{2}{|c|}{ ECOG performance status, n (\%) } \\
\hline $0-1$ & $52(85 \%)$ \\
\hline $2-4$ & $9(15 \%)$ \\
\hline \multicolumn{2}{|c|}{ Pretreatment EGFR status, n (\%) } \\
\hline Exon19 deletion & $37(61 \%)$ \\
\hline Exon21 L858R & $19(31 \%)$ \\
\hline Other & $5(8 \%)$ \\
\hline \multicolumn{2}{|l|}{ EGFR TKI, n (\%) } \\
\hline Gefitinib & $49(80 \%)$ \\
\hline Erlotinib & $7(12 \%)$ \\
\hline 2nd generation & $5(8 \%)$ \\
\hline
\end{tabular}

Abbreviations: ECOG eastern cooperative oncology group, EGFR epidermal growth factor receptor, TKI tyrosine kinase inhibitor

\section{Rebiopsy}

Table 3 depicts characteristics of rebiopsy sites, specimens, and procedures in patients who had undergone rebiopsy after developing acquired resistance to EGFRTKIs. Because of their easy accessibility and practical necessity, serous effusions such as pleural effusion and cerebrospinal fluid account for more than half of the specimens. Pulmonary lesions were also rebiopsied, with the most common procedure being transbronchial biopsy. Biopsy samples from lymph nodes or other sites were obtained using computed tomography-guided or sonography-guided needle biopsy. All rebiopsies were performed after stopping EGFR-TKI treatment.

\section{Resistance mechanisms}

A total of 61 rebiopsy samples were analyzed for EGFR mutations. Twenty-seven rebiopsy samples were analyzed using our tumor genotyping panel, and 34 samples were examined for EGFR mutations by commercial clinical laboratories. All of 61 patients had EGFR activating mutations before EGFR-TKI treatment, and 55 patients (90.2\%) still had same EGFR mutations in rebiopsy samples. T790M mutation was identified in 21 of 61 samples (34.4\%; Fig. 1). No samples had small cell histologic transformation. In samples analyzed using our tumor genotyping panel, $M E T$ gene copy number gain was seen in two of 27 samples (7\%). Additionally, we detected 
Table 3 Procedures and specimens of rebiopsy samples obtained from NSCLC patients with EGFR mutations

\begin{tabular}{ll}
\hline Procedure and specimen & Number \\
\hline Surgery & 3 \\
Brain & 2 \\
Lung & 1 \\
Autopsy & \\
Biopsy & 15 \\
Lung & 3 \\
Lymph node & 4 \\
Other & \\
Fluid & 24 \\
Pleural effusion & 8 \\
Cerebrospinal fluid & 1 \\
Cardiac effusion & 24 \\
\hline
\end{tabular}

PIK3CA mutation (E542K), BRAF mutation (G466V), and KRAS mutation (G12D), in one sample each in 27 samples (4\%) (Fig. 2). Six of 61 rebiopsy samples (9.8\%) did not possess EGFR mutation, despite having EGFR activating mutations at the initial analysis. KRAS mutation was detected in 1 of these samples.

\section{T790M prevalence}

Correlations between patient characteristics and T790M prevalence were evaluated (Table 4). Eleven of 20 patients who received continuous treatment with EGFRTKI after disease progression had T790M mutation in the rebiopsy sample. However, only 10 of 41 patients who had finished EGFR-TKI treatment at the time of disease progression had T790M mutation (Fig. 3). The frequency of T790M mutation in patients who received continued treatment with EGFR-TKI after disease progression was significantly higher than in patients who finished EGFR-TKI at diagnosis of disease progression (55\% versus $24 \%, p=0.018$ ). Multivariate analysis also demonstrated that continuous treatment with EGFR-TKI

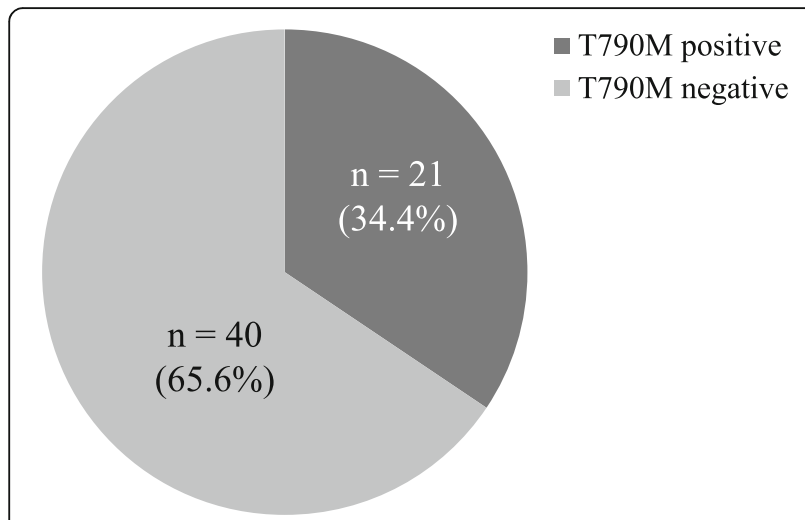

Fig. 1 Frequency of T790M mutation in rebiopsy samples $(n=61)$

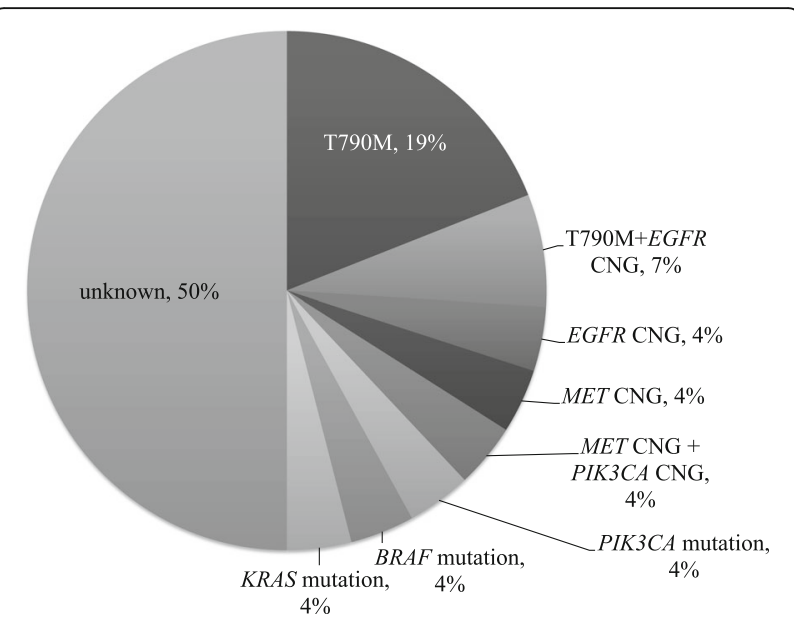

Fig. 2 Multimutational profiling in rebiopsy samples analyzed using our tumor genotyping panel $(n=27)$. CNG: Copy number gain

after disease progression was significantly correlated with T790M mutation (Table 4). Other characteristics, including PFS with EGFR-TKI, rebiopsy site, and rebiopsy sample, had no statistical association with the prevalence of T790M.

\section{Discussion}

Previous reports from examining patients in western countries have reported EGFR T790M mutation in 4969\% patients with NSCLC harboring EGFR mutations who had undergone rebiopsy after developing acquired resistance to EGFR-TKIs [11, 12, 20]. In contrast, our study identified T790M mutation in only 21 of 61 rebiopsy samples $(34.4 \%)$. This finding is similar to that of the one other Japanese study we are aware of [21]. Therefore, T790M prevalence in Japanese and Western patients may be different. In our study, only $30 \%$ of patients received continuous treatment with EGFR-TKI after disease progression. Shimilarly, few such patients were included in the study from Hata et al. [21]. However, 88-91\% of patients in previous studies from western countries received continuous treatment with EGFR-TKI after disease progression [12, 20]. Additionally, the frequency of T790M mutation in patients who received continuous treatment with EGFR-TKI after disease progression was significantly higher than that in patients who had finished EGFR-TKI treatment by diagnosis of disease progression in our study. Furthermore, the preclinical report showed that continuous exposure to EGFR-TKIs induced T790M mutation in a NSCLC cell line with an EGFR-sensitive mutation [22]. These data suggest that continued treatment with EGFR-TKIs after disease progression may promote T790M mutation. While differences in ethnicity and analysis methods may underlie these inconsistencies, the potential for EGFR-TKIs to promote T790M mutation should not be overlooked. 
Table 4 Multivariate and univariate analyses of patient characteristics and T790M prevalence in patients with NSCLC harboring EGFR mutations, who had undergone rebiopsy after acquired resistance to EGFR-TKI $(n=61)$

\begin{tabular}{|c|c|c|c|c|}
\hline Patient characteristics & Number & T790M (\%) & $P$ (Univariate) & $P$ (Multivariate) \\
\hline \multicolumn{3}{|l|}{$\overline{\text { Age }}$} & \multicolumn{2}{|l|}{0.9292} \\
\hline$\geq 75$ & 12 & $4(33 \%)$ & & \\
\hline$<74$ & 49 & $17(35 \%)$ & & \\
\hline \multicolumn{3}{|l|}{ Sex } & \multicolumn{2}{|l|}{0.4904} \\
\hline Female & 44 & $14(32 \%)$ & & \\
\hline Male & 17 & $7(41 \%)$ & & \\
\hline \multicolumn{3}{|l|}{ Smoking history } & \multicolumn{2}{|l|}{0.4904} \\
\hline Never & 44 & $14(32 \%)$ & & \\
\hline Former/current & 17 & 7 (41\%) & & \\
\hline \multicolumn{3}{|l|}{ EGFR mutation status } & \multicolumn{2}{|l|}{0.1038} \\
\hline Exon19 deletion & 37 & $9(24 \%)$ & & \\
\hline Exon21 L858R & 19 & $9(47 \%)$ & & \\
\hline Other & 5 & $3(60 \%)$ & & \\
\hline \multicolumn{3}{|l|}{ Rebiopsy site } & \multirow[t]{3}{*}{0.5813} & \multirow[t]{3}{*}{0.9133} \\
\hline Central nervous system & 11 & $3(27 \%)$ & & \\
\hline Other & 50 & $18(36 \%)$ & & \\
\hline \multicolumn{3}{|l|}{ Rebiopsy sample } & \multirow[t]{3}{*}{0.2017} & \multirow[t]{3}{*}{0.5016} \\
\hline Tissue & 28 & $12(43 \%)$ & & \\
\hline Fluid & 33 & $9(27 \%)$ & & \\
\hline \multicolumn{3}{|l|}{ EGFR TKI } & \multirow{4}{*}{\multicolumn{2}{|c|}{0.1208}} \\
\hline Gefitinib & 49 & $17(35 \%)$ & & \\
\hline Erlotinib & 7 & $4(57 \%)$ & & \\
\hline 2nd generation & 5 & $0(0 \%)$ & & \\
\hline \multicolumn{3}{|l|}{ Line of EGFR-TKI } & \multirow{3}{*}{\multicolumn{2}{|c|}{0.4235}} \\
\hline $1 \mathrm{st}$ & 39 & $12(31 \%)$ & & \\
\hline 2nd or later & 22 & $9(41 \%)$ & & \\
\hline \multicolumn{3}{|c|}{ History of platinum doublet until rebiopsy } & \multirow{3}{*}{\multicolumn{2}{|c|}{0.7021}} \\
\hline Yes & 34 & $11(32 \%)$ & & \\
\hline No & 27 & $10(37 \%)$ & & \\
\hline \multicolumn{3}{|l|}{ PFS with EGFR-TKI } & \multirow{3}{*}{\multicolumn{2}{|c|}{0.4823}} \\
\hline$\geq 10$ months & 34 & $13(38 \%)$ & & \\
\hline$<10$ months & 27 & $8(30 \%)$ & & \\
\hline \multicolumn{3}{|c|}{ Interval between RECIST PD and rebiopsy } & \multirow{3}{*}{\multicolumn{2}{|c|}{0.2766}} \\
\hline$\geq 4$ months & 29 & $12(41 \%)$ & & \\
\hline$<4$ months & 32 & $9(28 \%)$ & & \\
\hline \multicolumn{3}{|c|}{ Period of continuation of TKI beyond PD } & \multirow[t]{3}{*}{0.0182} & \multirow[t]{3}{*}{0.0417} \\
\hline$\geq 30$ days & 20 & $11(55 \%)$ & & \\
\hline$<30$ days & 41 & $10(24 \%)$ & & \\
\hline
\end{tabular}

Abbreviations: EGFR epidermal growth factor receptor, TKI tyrosine kinase inhibitor, PFS progression free survival, $P D$ progressive disease

The frequencies of $M E T$ gene copy number gain and PIK3CA mutation in our study were similar to those previously reported in studies from western countries $[11,12]$. Furthermore, BRAF mutation is associated with acquired resistance to EGFR-TKIs [16]. We also detected
KRAS mutation in one rebiopsy sample. KRAS and EGFR mutations have previously been considered mutually exclusive [23]. However, Kuiper et al. recently reported KRAS mutation in one rebiopsy sample following development of acquired resistance to EGFR-TKIs [24]. 


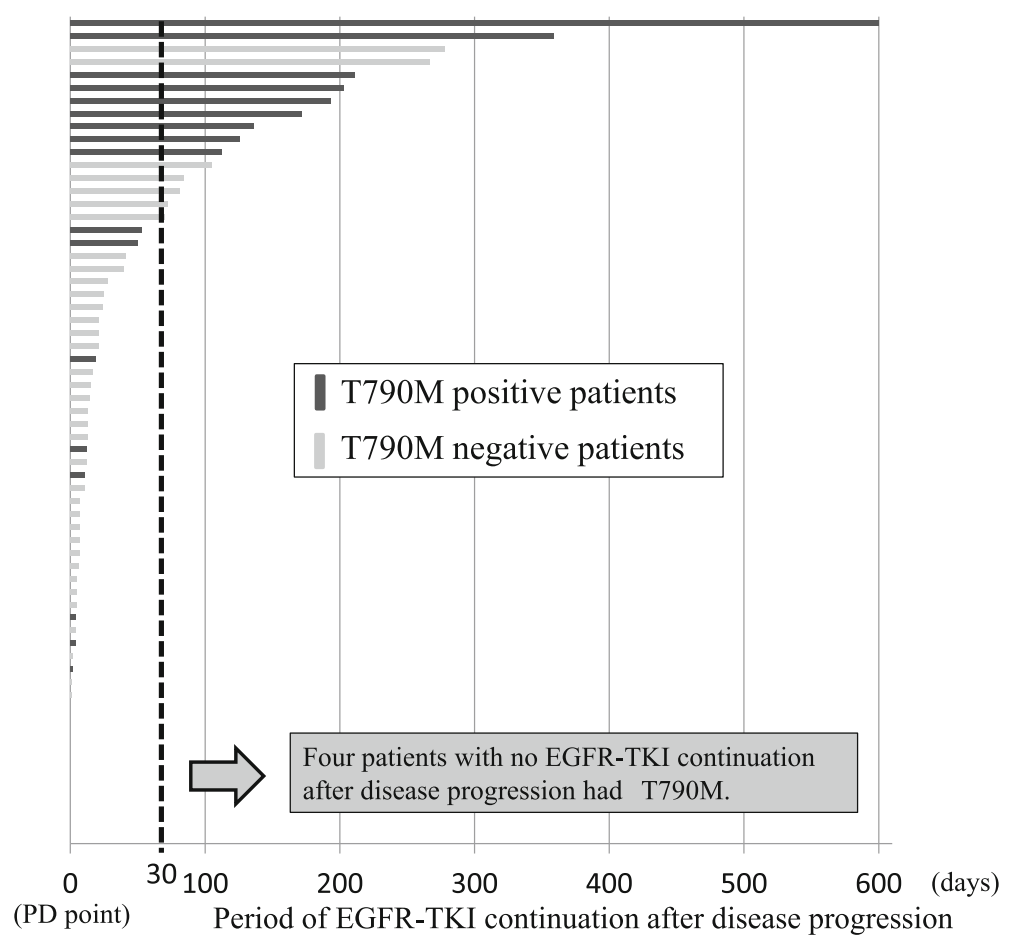

Fig. 3 Relationship of EGFR-TKI continuation beyond progressive disease and T790M prevalence

Furthermore, Li et al. have identified double mutation of EGFR and KRAS in pretreatment assessment of NSCLC patients [25]. These data suggest that KRAS mutation may promote acquired resistance to EGFR-TKIs through drug selective pressure. However, more data are required to confirm this hypothesis.

The availability of continuous treatment with EGFRTKIs after disease progression is still controversial. In IMPRESS trial, continuation of gefitinib treatment after disease progression on gefitinib monotherapy did not prolong progression-free survival and overall survival in patients who received platinum-based doublet chemotherapy as subsequent line of treatment [26]. However, it is unclear that the efficacy of continuous using EGFR-TKIs without platinum doublets [27, 28]. Recently, we had been able to use third generation EGFR-TKIs that have great efficacy for NSCLC with EGFR T790M mutation in clinical practice. If there are relationship between the continuous treatment with EGFR-TKIs after disease progression and the frequency of $\mathrm{T} 790 \mathrm{M}$, the continuous therapy can be more important choice.

Our study had several limitations. First, we retrospectively collected the data from a single institution, and our sample size was small. This small sample size results from the difficulty surrounding rebiopsy in clinical practice. Second, we analyzed only 27 rebiopsy samples (44.3\%) using our tumor genotyping panel. Therefore, further multi-institutional studies are warranted to verify our results.

\section{Conclusions}

The frequency of T790M mutation in rebiopsy samples in our study was lower than that reported in previous reports studies of western patients. The frequency of T790M mutation in patients who received continuous treatment with EGFR-TKIs after disease progression was significantly higher than that in patients who stopped EGFR-TKI treatment at diagnosis of disease progression. Continuous treatment with EGFR-TKI following disease progression may therefore influence the frequency of EGFR T790M mutations in rebiopsy samples.

\section{Additional file}

Additional file 1: The detail of mutational analysis. (DOCX $22 \mathrm{~kb}$ )

\section{Abbreviations}

EGFR: Epidermal growth factor receptor; EMT: Epithelial-to-mesenchymal transition; NSCLC: Non-small cell lung cancer; OS: Overall survival; PCR: Polymerase chain reaction; PFS: Progression-free survival; SCLC: Small cell lung cancer; TKI: Tyrosine kinase inhibitor

\section{Acknowledgments}

We thank all the patients who participated in this study and their families. We also thank Ms. Mie Yamada (Division of Thoracic Oncology, Shizuoka Cancer Center) for data management; Mr. Masato Abe (Division of Pathology, Shizuoka Cancer Center), Ms. Akane Naruoka, and Ms. Junko Suzuki (Division 
of Drug Discovery and Development, Shizuoka Cancer Center Research Institute) for sample preparation and analysis, Dr. Tomohiro Maniwa, Dr. Shoji Takahashi, Dr. Masashi Nagata, Dr. Yoshikane Yamauchi, Dr. Naoko Miyata, Dr. Hideaki Kojima, and Dr. Haruhiko Kondo (Division of Thoracic Surgery); and Dr. Takuya Oyakawa, Dr. Yasushi Hisamatsu, Dr. Shota Omori, Dr. Kazuhisa Nakashima, Dr. Yukiko Nakamura, Dr. Asuka Tsuya, Dr. Takaaki Tokito, Dr. Hirofumi Eida, and Dr. Chikara Sakaguchi (Division of Thoracic Oncology, Shizuoka Cancer Center) for their contributions to this study.

\section{Funding}

This work was supported by JSPS KAKENHI Grant Numbers 24591186 (NY) and 24501363 (YK).

\section{Availability of data and materials}

The datasets supporting the conclusions of this article are included within the manuscript and Additional file 1.

\section{Authors' contributions}

RK contributed to the drafting of this manuscript and data collection, and HK contributed to the study design and statistical analysis. MS, YK contributed to analysis of the samples using our tumor genotyping panel. KW, AO, TT, $T N, H M, M I, M E, T N, Y O, N Y, K T$, and TT contributed to analysis of the data and interpretation of the findings. All authors have read and approved the submission of the final manuscript.

\section{Competing interest}

The authors declare that they have no competing interest.

\section{Consent for publication}

Not applicable

\section{Ethics approval and consent to participate}

This study protocol was approved by the Institutional Review Board of Shizuoka Cancer Center under number 27-J102-27-1-3. The individual consent was waived because this study was retrospective in design and based on anonymous data.

\section{Author details}

'Division of Thoracic Oncology, Shizuoka Cancer Center, 1007 Shimonagakubo, Nagaizumi-cho, Sunto-gun, Shizuoka 411-8777, Japan. ${ }^{2}$ Department of Respiratory Medicine, Juntendo University Graduate School of Medicine, 2-1-1 Hongo, Bunkyo-ku, Tokyo 113-8421, Japan. ${ }^{3}$ Drug Discovery and Development Division, Shizuoka Cancer Center Research Institute, 1007 Shimonagakubo, Nagaizumi-cho, Sunto-gun, Shizuoka 411-8777, Japan. ${ }^{4}$ Third Department of Internal Medicine, Wakayama Medical University, 811-1 Kimiidera, Wakayama 641-8509, Japan. ${ }^{5}$ Division of Thoracic Surgery, Shizuoka Cancer Center, 1007 Shimonagakubo, Nagaizumi-cho, Sunto-gun, Shizuoka 411-8777, Japan. ' $D$ ivision of Diagnostic Radiology, Shizuoka Cancer Center, 1007 Shimonagakubo, Nagaizumi-cho, Sunto-gun, Shizuoka 411-8777, Japan. ${ }^{7}$ Division of Diagnostic Pathology, Shizuoka Cancer Center, 1007 Shimonagakubo, Nagaizumi-cho, Sunto-gun, Shizuoka 411-8777, Japan

\section{Received: 26 January 2016 Accepted: 30 October 2016}

\section{Published online: 08 November 2016}

\section{References}

1. Herbst RS, Heymach JV, Lippman SM. Lung Cancer. N Engl J Med. 2008:359:1367-80.

2. Matsuda T, Marugame T, Kamo K, Katanoda K, Ajjki W, Sobue T, et al. Cancer incidence and incidence rates in Japan in 2002: based on data from 11 population-based cancer registries. Jpn J Clin Oncol. 2008;38(9):641-8.

3. Travis WD, Travis LB, Devesa SS. Lung Cancer. Cancer. 1995;75:191-202.

4. Maemondo M, Inoue A, Kobayashi K, Sugawara S, Oizumi S, Isobe H, et al. Gefitinib of chemotherapy for non-small-cell lung cancer with mutated EGFR. N Engl J Med. 2010;362:2380-8.

5. Mitsudomi T, Morita S, Yatabe Y, Negoro S, Okamoto I, Tsurutani J, et al. Gefitinib versus cisplatin plus docetaxel in patients with non-small-cell lung cancer harbouring mutations of the epidermal growth factor receptor (WJTOG3405): an open label, randomised phase 3 trial. Lancet Oncol. 2010;11:121-8
6. Zhou C, Wu YL, Chen G, Feng J, Liu XO, Wang C, et al. Erlotinib versus chemotherapy as first-line treatment for patients with advanced EGFR mutation-positive non-small-cell lung cancer (OPTIMAL, CTONG-0802): a multicentre, open-label, randomised, phase 3 study. Lancet Oncol. 2011;12:735-42.

7. Rosell R, Carcereny E, Gervais R, Vergnenegre A, Massuti B, Felip E, et al. Erlotinib versus standard chemotherapy as first-line treatment for European patients with advanced EGFR mutation-positive non-small-cell lung cancer (EURTAC): a multicentre, open-label, randomised phase 3 trial. Lancet Oncol. 2012;13:239-46.

8. Sequist LV, Yang JCH, Yamamoto N, O'Byrne K, Hirsh V, Mok T, et al. Phase III study of afatinib or cisplatin plus pemetrexed in patients with metastatic lung adenocarcinoma with EGFR mutations. J Clin Oncol. 2013;31:3327-34.

9. Kobayashi S, Boggon TJ, Dayaram T, Janne PA, Kocher O, Meyerson M, et al. EGFR mutation and resistance of non-small-cell lung cancer to gefitinib. N Engl J Med. 2005;352:786-92.

10. Pao W, Miller VA, Politi KA, Riely GJ, Somwar R, Zakowski MF, et al. Acquired resistance of lung adenocarcinomas to gefitinib or erlotinib is associated with a second mutation in the EGFR kinase domain. PLoS Med. 2005;2(3):e73

11. Sequist LV, Waltman BA, Dias-Santagata D, Digumarthy $S$, Turke AB, Fidias $P$, et al. Genotypic and histological evolution of lung cancers acquiring resistance to EGFR inhibitors. Sci Transl Med. 2011;3:75ra26.

12. Yu HA, Arcila ME, Rekhtman N, Sima CS, Zakowski MF, Pao W, et al. Analysis of tumor specimens at the time of acquired resistance to EGFR-TKI therapy in 155 patients with EGFR-mutant lung cancers. Clin Cancer Res. 2013;19(8):2240-7.

13. Yun $\mathrm{CH}$, Mengwasser KE, Toms AV, Moo MS, Greukich H, Wong KK, et al. The T790M mutation in EGFR kinase causes drug resistance by increasing the affinity for ATP. Proc Natl Acad Sci U S A. 2008;105:2070-5.

14. Engelman JA, Zejnullahu K, Mitsudomi T, Song Y, Hyland C, Park JO, et al. MET amplification leads to gefitinib resistance in lung cancer by activating ERBB3 signaling. Science. 2007;316:1039-43.

15. Ji W, Choi CM, Rho JK, Jang SJ, Park YS, Chun SM, et al. Mechanisms of acquired resistance to EGFR-tyrosine kinase inhibitor in Korean patients with lung cancer. BMC Cancer. 2013;13:606.

16. Ohashi K, Sequist LV, Arcila ME, Moran T, Chmielecki J, Lin TL, et al. Lung cancers with acquired resistance to EGFR inhibitors occasionally harbor BRAF gene mutations but lack mutations in KRAS, NRAS, or MEK1. Proc Natl Acad Sci U S A. 2012;109(31):E2127-33.

17. Jackman D, Pao W, Riely GJ, Engelman JA, Kris MG, Janne PA, et al. Clinical definition of acquired resistance to epidermal growth factor receptor tyrosine kinase inhibitors in non-small-cell lung cancer. J Clin Oncol. 2009;28:357-60.

18. Serizawa M, Koh $\mathrm{Y}$, Kenmotsu H, Isaka M, Murakami H, Akamatsu $H$, et al. Assesment of mutational profile of Japanese lung adenocarcinoma patients by multitarget assays. Cancer. 2014;120:1471-81.

19. Eisenhauser EA, Therasse P, Bogaerts J, Schwartz LH, Sargent D, Ford R, et al. New response evaluation criteria in solid tumours: revised RECIST quideline (version 1.1.). Eur J Cancer. 2009:45:228-47.

20. Oxnard GR, Arcila ME, Sima CS, Riely GJ, Chmielecki J, Kris MG, et al. Acquired resistance to EGFR tyrosine kinase inhibitors in EGFR-mutant lung cancer: distinct natural history of patients with tumors harboring the T790M mutation. Clin Cancer Res. 2011;17:1616-22.

21. Hata A, Katakami N, Yoshioka H, Takeshita J, Tanaka K, Nanjo S, et al. Rebiopsy of non-small cell lung cancer patients with acquired resistance to epidermal growth factor receptor-tyrosine kinase inhibitor. Cancer. 2013:119:4325-32.

22. Ogino A, Kitao H, Hirano S, Uchida A, Ishiai M, Kozuki T, et al. Emergence of epidermal growth factor receptor T790M mutation during chronic exposure to geitinib in a non-small cell lung cancer cell line. Cancer Res. 2007:67(16):7807-14

23. Kosaka T, Yatabe $\mathrm{Y}$, Endoh $\mathrm{H}$, Yoshida K, Hida T, Tsuboi M, et al. Analysis of epidermal growth factor receptor gene mutation in patients with non-small cell lung cancer and acquired resistance to gefitinib. Clin Cancer Res. 2006;12(19):5764-9.

24. Kuiper JL, Heideman DAM, Thunnissen E, Paul MA, Wijk AWV, Postmus PE, et al. Incidence of T790M mutation in (sequential) rebiopsies in EGFRmutated NSCLC-patients. Lung Cancer. 2014;85:19-24.

25. Li S, Li L, Zhu Y, Huang C, Qin Y, Liu H, et al. Coexistence of EGFR with KRAS, or BRAF, or PIK3CA somatic mutations in lung cancer: a 
comprehensive mutation profiling from 5125 Chinese cohorts. Br J Cancer. 2014;110(11):2812-20

26. Soria JC, Wu YL, Nakagawa K, Kim SW, Yang JJ, Ahn MJ, Wang J, et al. Gefitinib plus chemotherapy after progression on first-line gefitinib (IMPRESS): a phase 3 randomised trial. Lancet Oncol. 2015;16:990-8.

27. Auliac JB, Fournier C, Valette CA, Perol M, Bizieux A, Vinas F, et al. Impact of continuing first-line EGFR tyrosine kinase inhibitor therapy beyond RECIST disease progression in patients with advanced EGFR-mutated non-small-cell lung cancer (NSCLC): retrospective GFPC 04-13 study. Target Oncol. 2016;11:167-74.

28. Chen Q, Quan Q, Ding L, Hong X, Zhou N, Liang Y, et al. Continuation of epidermal growth factor receptor tyrosine kinase inhibitor treatment prolongs disease control in non-small-cell lung cancers with acquired resistance to EGFR tyrosine kinase inhibitors. Oncotarget. 2015;6:24904-11.

Submit your next manuscript to BioMed Central and we will help you at every step:

- We accept pre-submission inquiries

- Our selector tool helps you to find the most relevant journal

- We provide round the clock customer support

- Convenient online submission

- Thorough peer review

- Inclusion in PubMed and all major indexing services

- Maximum visibility for your research

Submit your manuscript at www.biomedcentral.com/submit
Biomed Central 